\section{Epistemología y posmodernismo. Los errores categoriales en Foucault y Vattimo}

Epistemology and postmodernism. Categorical errors in Foucault and Vattimo

\author{
Héctor Cáceres Bejarano
}

\section{RESUMEN}

El pensamiento posmoderno es un sistema de ideas y creencias que se ha ido extendiendo progresivamente dentro de las ciencias sociales y en la sociedad. Se trata de formas de pensar y actuar que destilan un marcado relativismo respecto al abordaje de la realidad. En lo que respecta a la ciencia, esto supone una problemática para la aproximación y compromiso objetivo por parte del investigador y en el desarrollo del conocimiento. Por ello, el presente artículo, pretende como objetivo hacer un análisis crítico desde el propio discurso en algunas de las obras referenciales de personajes icónicos del posmodernismo, como son Michel Foucault y Gianni Vattimo; respecto a los conceptos de verdad, ciencia y objetividad. Para tal fin, se hace uso de una metodología cualitativa y hermenéutica, desde la revisión y análisis documental, identificando ideas y sentencias que denoten errores categoriales y falacias argumentales. Así, como resultados, tenemos que tanto Foucault como Vattimo, son recurrentes al realizar generalizaciones indebidas desde casos muy particulares o haciendo atribuciones causales impropias a hechos más complejos; al igual que hacer inadecuadas vinculaciones, comparaciones o aproximaciones respecto a temas, dimensiones o categorías diferentes de la realidad como son el desarrollo científico y la política, la ciencia y el arte, entre otros. Ante ello, se debe procurar un equilibrio en el razonamiento que integre lo subjetivo y lo objetivo, sin caer en reduccionismos o generalizaciones indebidas. Para ello se hace necesario el uso adecuado de diferentes metodologías, pero abordando la realidad en sus respectivos marcos categoriales.

Palabras clave: Posmodernismo; epistemología; error categorial; falacia argumental

\section{ABSTRACT}

Postmodern thought is a system of ideas and beliefs that has been progressively spreading within the social sciences and society. It involves ways of thinking and acting that exhibit a marked relativism about the approach to reality. As far as science is concerned, this is a problem for the approach and objective commitment on the part of the researcher and in the development of knowledge. Therefore, this article aims to make a critical analysis from the discourse itself in some of the referential works of iconic characters of postmodernism, such as Michel Foucault and Gianni Vattimo, regarding the concepts of truth, science and objectivity. To this effect, a qualitative and hermeneutic methodology is used, from the review and analysis of documents, identifying ideas and sentences that denote categorical errors and argumentative fallacies. Thus, as results, we can say about Foucault and Vattimo, are recurrent in making undue generalizations from very particular cases or making improper causal attributions to more complex facts; as well as making inadequate links, comparisons or approximations regarding issues, dimensions or different categories of reality such as scientific development and politics, science and art, among others. In view of this, a balance must be sought in reasoning that integrates the subjective and the objective, without falling into reductionism or undue generalizations. This requires the appropriate use of different methodologies, but approaching reality within their respective categorical frameworks.

Keywords: Postmodernism; epistemology; categorical error; argumentative fallacy

\section{RELIGACIÓN \\ REVISTA DE CIENCIAS SOCIALES Y HUMANIDADES JOURNAL OF SOCIAL SCIENCES AND HUMANITIES REVISTA DE CENCIAS SOCIAIS E HUMANAS}

INFORMACIÓN:

http://doi.org/10.46652/rgn.v6i30.854 ISSN $2477-9083$

Vol. 6 No. 30, 2021. e210854 Quito, Ecuador

Enviado: octubre 04, 2021

Aceptado: diciembre 06, 2021

Publicado: diciembre 16, 2021

Publicación Continua

Sección General | Peer Reviewed

\section{AUTOR:}

(D) Héctor Cáceres Bejarano

Universidad Nacional Mayor de San Marcos - Perú

hector.caceres@unmsm.edu.pe

Conflicto de intereses

El autor declara que no existe conflicto de interés posible.

Financiamiento

No existió asistencia financiera de partes externas al presente artículo.

Agradecimiento

N/A

Nota

El artículo forma parte de uno de los temas de investigación en la tesis para sustentación de maestría denominado:

El subjetivismo epistemológico posmoderno, su influencia colonial y las repercusiones en la investigación y producción científica de las principales instituciones académicas de las ciencias sociales en el Perú. Efectos en la realidad política, social y cultural peruana.

ENTIDAD EDITORA 


\section{Introducción}

Las universidades e institutos del siglo XXI cumplen una función fundamental en el desarrollo de sus futuros profesionales y en la investigación científica. En ese sentido es importante como bien sostiene Guerra (2011), el poner énfasis en el desarrollo de la narrativa y la ciencia; el saber escribir, investigar y hacerlo apropiadamente. Del mismo modo, la ciencia del siglo XXI exige el dominio de los sistemas complejos e interactivos procurando un trabajo científico interdisciplinario (Gavela, 2011). Y particularmente, es importante abordar su epistemología, pues hay mucho desconocimiento de ello (Paz y Miño, 2019).

Asimismo, desde el último cuarto del siglo XX y comienzos del XXI encontramos diferentes personajes que realizan una crítica o cuestionamiento de la propuesta filosófica, epistemológica o de investigación de la ciencia moderna; la cual se sintetiza en su pretendida búsqueda de objetividad y verificación, falsación o corroboración de las ideas o hechos, además del progreso. Desde su perspectiva, tanto los grandes sistemas filosóficos, económicos, políticos y religiosos como el liberalismo, el marxismo, el cristianismo y otros no han podido satisfacer las expectativas de liberación, paz, igualdad, justicia, bienestar y felicidad del ser humano en las sociedades. Esta perspectiva, denominada como pensamiento posmoderno, considera que más bien, se ha agravado la situación de la humanidad o se ha atentado contra esta por las derivaciones ocasionadas en su desarrollo. En síntesis, según Casullo (2004), en la visión de la posmodernidad se trata del agotamiento del proyecto de la modernidad en cuanto a la dimensión de los grandes relatos legitimadores enmarcados en filosofías de la historia.

Además, el posmodernismo considera que toda forma de leyes, principios, estructuras o formas de razonamiento que definen lo verdadero y lo falso; se encuentran condicionadas por su contexto socio cultural e histórico y particularmente por relaciones de poder. Es decir, la influencia de intereses políticos, económicos, religiosos, culturales y otros aspectos externos del ámbito de producción del conocimiento a lo largo de la historia; siendo pues toda definición de lo correcto, objetivo o establecido, algo arbitrario o impuesto, sujeto a convenciones que nunca son neutras.

Ante estos planteamientos, el presente artículo pretende como objetivo, realizar un análisis crítico desde el propio discurso posmoderno, dentro de un enfoque epistemológico; atendiendo los elementos categoriales y argumentales de análisis que se utilizan en el trasfondo de la crítica posmoderna para el abordaje de la realidad. Para ello, se toman como campos y obras referenciales, algunos de los principales trabajos temáticos narrativos que M. Foucault y G. Vattimo abordan y cuestionan respecto a los temas de la ciencia, la verdad y la objetividad.

\section{Metodología}

Para efectos del desarrollo de este trabajo, se ha recurrido al enfoque cualitativo, haciendo una hermenéutica de los discursos desde la revisión y análisis documental. Se seleccionó principalmente algunos de los trabajos narrativos referenciales de M. Foucault y G. Vattimo, en lo que respecta a sus impresiones sobre los temas de la verdad, el conocimiento, la ciencia y la objetividad; siendo estos textos muy puntuales al respecto. Dichos textos son por parte de Michel Foucault los siguientes: El orden del discurso (2005), La historia de la sexualidad. 
La voluntad de saber (2007), Estrategias de poder (1999) y Lecciones sobre la voluntad de saber: curso en el Collège de France (1970 - 1971) (2014). Y por parte de Gianni Vattimo: El fin de la modernidad (1987), No ser Dios (2008) y Adiós a la verdad (2012). Así, dentro de sus contenidos se hizo una selección de diferentes ideas y sentencias en sus respectivos contextos, que evoquen de manera muy clara y sintética las referencias específicas de los autores respecto a los temas de la verdad, el conocimiento, la ciencia y la objetividad. Luego se procedió al análisis de las proposiciones en sus relaciones lógicas conceptuales y argumentales. De este modo, se procedió a identificar los elementos dentro de las falacias argumentales no formales, las cuales se caracterizan por tener un error en el razonamiento que se evidencia en el contenido mismo de las premisas; estando entre ellas principalmente la falacia ad veracundiam o falacia de autoridad, que supone asumir la veracidad de una proposición apelando a una autoridad como garantía absoluta, por ejemplo al presentar al psicoanálisis o las teorías de Sigmund Freud, algo muy recurrente en las ciencias sociales particularmente. Otro tipo de falacia es la de generalización apresurada, esta se expresa al realizar conclusiones anticipadas o exageraciones desde algunos o pocos casos que sustenten un hecho, no teniendo la fundamentación suficiente. También está la falacia argumental de correlación y causalidad, que se expresa al afirmar y relacionar una causa sin la evidencia suficiente. $Y$ además, tenemos a las falacias por generalizaciones con conclusiones que son inatingentes, al no tener relación con el trasfondo del tema. Por otro lado, se identificarán errores categoriales según la conceptualización de Gilbert Ryle; lo cual supone el error en relacionar de manera indebida, las ideas o sistemas conceptuales y sus propias dinámicas entre campos o dimensiones muy diferentes para el abordaje y análisis de la realidad. Por ejemplo, tenemos el caso de los sistemas conceptuales y de dinámicas de desarrollo metodológico de la ciencia, en comparación con las diferentes expresiones de los campos artísticos; así como los de la ciencia respecto a los de la política, entre otros.

\section{Observaciones sobre errores categoriales y falacias argumentales en el pensamiento posmoderno.}

Entrando en un mayor detalle, para tratar el tema de los errores categoriales no se puede soslayar a Gilbert Ryle (1949) y su libro El concepto de mente. Ryle es un filósofo y lógico británico, exponente importante de la denominada Escuela de Oxford. Este es influenciado por la obra de Wittgenstein y considera a la filosofía como un análisis lingüístico, siendo uno de los que sientan las bases de la llamada filosofía analítica. Así, desde su filosofía del lenguaje asume su crítica a determinadas situaciones erróneas de enfoque o abordaje de los fenómenos de estudio, por el uso inadecuado de conceptos en sus relaciones categoriales. En tal sentido por ejemplo, Ryle plantea un rechazo al falso dualismo o dicotomía cartesiana de mente y cuerpo, como si estas fueran dos dimensiones totalmente diferentes y contradictorias, siendo un error categorial de aproximación para abordar dichos temas. Esto supone la importancia de tener cuidado en utilizar determinadas etiquetas o categorías para definir ciertos hechos o fenómenos. Y con mayor razón, el adecuado uso metodológico para establecer algún tipo de relación descriptiva, comparativa o explicativa sin caer en contradicciones o sin sentidos. De esta manera, los errores categoriales se caracterizan por pretender unir o hacer uso indebidamente de diferentes conceptos mediante conjunciones o disyunciones, siendo dichos conceptos de diferentes clasificaciones o categorías para los análisis, al pertenecer a planos muy distintos de la realidad. 
Entre otros ejemplos veremos los casos de relacionar campos como la ciencia y sus sistemas de conceptos con el arte y la poesía o los criterios políticos con los científicos para establecer razones y conclusiones que definan determinadas ideas o hechos.

En lo que respecta a las falacias argumentales, estas pueden entenderse como razonamientos equivocados o distorsionados, exagerados, tendenciosos, injustificados o engañosos; los cuales son utilizados de manera consciente o inconsciente para defender o justificar una creencia, idea o una particular interpretación de un hecho; así como la generación de una opinión favorable prescindiendo de las necesarias y justas validaciones lógicas racionales.

De tal forma que, las falacias argumentales y los errores categoriales generan confusión o una falsa confianza y sirven para sorprender a los interlocutores, aprovechar ciertos rasgos susceptibles de las personas, sus inquietudes, sesgos o conflictos existenciales apelando desde su subjetividad; además de aprovechar una audiencia poco formada, desatenta o descuidada en el análisis de la realidad expresada en las ideas y los hechos.

Los errores categoriales y las falacias argumentales, en este caso no formales, claramente tienen consecuencias en las ciencias. Ya que es necesaria la rigurosidad en la descripción de la realidad, además de la homogeneidad en los códigos, signos y observaciones sin ambigüedades o defectos de polisemia, para una adecuada sistematización, orden y categorización de los datos y su potencial transformación en información y conocimiento objetivo después de su adecuada interpretación y comprensión. Sin embargo, estos aspectos son cuestionados o minimizados en el pensamiento posmoderno. Pues se prefiere diluirlo todo, lo verdadero y lo falso, lo sano y hasta lo patológico; invisibilizando u oscureciendo las diferencias en las ideas, objetos y hechos; mezclando temas o dimensiones de análisis diferentes, pretendiendo justificar posturas ideológicas dentro de una retórica que expone la idea de la libertad individual y los derechos como aspectos centrales suficientes para disminuir o invalidar cualquier otra reflexión o cuestionamiento. En suma, generar la creencia, curiosamente determinista, de que no existe objetividad, certezas ni verdades, tan solo opiniones.

En ese sentido, como se dijo, el posmodernismo asume particularmente una posición dentro del subjetivismo, entendiéndose desde la prevalencia del mundo vitalista y afectivo, dando legitimidad al arte y a la literatura, por ejemplo, como fuentes comprensivas de la "realidad" o realidades según el parecer de cada uno; a través de la puesta en relieve del ámbito interpretativo y reactivo de las propias percepciones. Se trata de la primacía del Ego expresado en el individualismo y el subjetivismo de la experiencia personal; ello a través de las emociones, sentimientos y pasiones, tanto como los deseos y múltiples interpretaciones; al igual que la manifestación de una dispuesta imaginación creativa para adornar o acomodar la realidad al gusto y conveniencia según el propio y libre deseo, bajo esa propia medida interpretativa subjetiva.

Se pretende de este modo, asumir estas interpretaciones como fuentes legítimas, no de una verdad ciertamente, pero sí de posturas u opiniones; haciendo en muchos casos reduccionismos, a veces de tipo ideológico, además de generalizaciones; incurriendo en falacias argumentales de diverso tipo. Pero lo que más interesa en el pensamiento posmoderno es la búsqueda de legitimación de una total libertad o liberalidad actitudinal como derecho personal incluso. De esta forma, campos como la literatura, la poesía y otros son equiparados con la ciencia 
indebidamente, cayendo en errores categoriales. Y es que para el posmoderno, ya no se trata de la búsqueda de la objetividad como algo esencial, pues ya no se reconoce validez a esta, sino más bien, de la pretensión de legitimación de las diferentes percepciones en las personas al creer que no existe una postura "objetiva” única y válida de la realidad. Y en tal sentido, hasta lo psicopatológico también podría normalizarse bajo el criterio del respeto de la libertad y el derecho entendiéndose como otras manifestaciones del Ser.

\subsection{En Gianni Vattimo}

Para Vattimo el conocimiento científico se reduce a una cuestión retórica, de convención social o de persuasión. Ciertamente no es un relativista absoluto, pues el solo hecho de plantear o aceptar esto sería un contrasentido para quienes postulan la pérdida o caída absoluta de las aproximaciones universales y la imposibilidad de poder plantear visiones, teorías únicas o integrales y explicativas de la realidad. Sin embargo, Vattimo tiene como referentes de su pensamiento a F. Nietzsche y M. Heidegger. Y los criterios de delimitación sobre el conocimiento que utiliza Vattimo, provienen de su influencia kuhniana y de Lyotard, afirmando que si bien no hay que asumir criterios absolutos y deterministas sobre las cosas; es posible conocer la realidad asumiendo y "verificando" los hechos desde las propias y variadas visiones paradigmáticas. Ello a pesar de la inherencia de las convenciones sociales o tradiciones al interior de la comunidad científica, siendo estas pequeñas aproximaciones una suerte de metaforización de la realidad.

Pero aun así, hay algo de contradicción al caer en errores categoriales y algunas falacias argumentales al conceder igual estatus de conocimiento a las diferentes ciencias sociales o humanísticas equiparándolas con las mismas artes; más aún al pretender legitimar el subjetivismo de las personas con todas las posibles metaforizaciones que se puedan hacer desde los deseos, percepciones, gustos y hasta caprichos existenciales. Esto bajo la imposición inexorable de la supuesta relevancia política de la libertad y los derechos civiles de las personas para toda dimensión de la realidad y el conocimiento, habiendo una vez más una colisión entre el desarrollo o búsqueda del conocimiento científico en sí mismo y la injerencia política, de las convenciones sociales o de la misma voluntad del pueblo en la determinación de las cosas según sus diferentes interpretaciones.

Esta visión epistemológica puede tener efectos muy serios si se pretende tener cierta objetividad en la construcción de la historia, el desarrollo de la antropología, la sociología y demás ciencias. Así como en pretender dar legitimación en la misma categoría del desarrollo del conocimiento a las ciencias sociales, humanísticas y otras con sus respectivos subcampos, entre ciencias básicas, aplicadas y tecnologías; con otras actividades como las artes, la literatura, la libre expresión y creatividad entre la novela y la poesía, además de la pintura y otras formas expresivas y subjetivas. Esto no implica una pretensión de minusvaloración o de dar más autoridad a un campo u otro; pues se trata solo de categorías diferentes de la realidad que deben ser abordadas en su respectivo espacio dentro de la cultura y la sociedad. 
Así, en su obra El fin de la modernidad (Vattimo, 1987) encontramos:

...toda argumentación que quiera fundar demostrativamente una elección entre paradigmas es necesariamente circular. Pero "cualquiera que sea su fuerza, la condición de la argumentación circular es solo la condición de la persuasión" (la cursiva es mía). A causa de este rasgo básico suyo vinculado con la persuasión más que con la demostración, la imposición de un paradigma en la historia de una ciencia tiene muchos, o todos, los rasgos de una "revolución científica": su difusión, su articulación, su establecimiento como canon de ulteriores elecciones operativas, de valoraciones y elecciones de gusto no se fundan efectivamente en un modo de adecuación a la verdad de las cosas, sino que se fundan en su "funcionalidad" respecto de una forma de vida, funcionalidad que sin embargo no se mide a su vez por criterios de "correspondencia", sino que ella misma es, circularmente objeto de persuasión más que de demostración (p. 84).

Vattimo asume que dentro del proceso del desarrollo del conocimiento solo hay retórica y que más bien un agente externo, la persuasión, es la fuente determinante de las "verdades" que se imponen. Se trata de una falacia argumental de tipo inducción indebida o de falsa generalización, además de falsa causa al tomar a la persuasión como principal o único factor; no se contempla la posibilidad de tantas otras alternativas incluyendo la misma capacidad, rigurosidad, honestidad, transparencia y sustentabilidad pertinente del mismo operador científico y de las instituciones para definir las ideas y los hechos objetivamente. Se cuestiona y generaliza indebidamente.

La verdad de una proposición científica no está en su verificación controlable atendiendo a reglas públicamente estipuladas y adoptadas idealmente por todos, lo cual sería un modo de reducir a su significación puramente formal y nexo de lógica y retórica, sino que en última instancia es, en cambio, la aceptación de las reglas de verificación vigentes en los ámbitos científicos particulares por parte de una esfera pública que es el logos - lenguaje común, tejido y retejido continuamente en términos retórico hermenéuticos, porque su sustancia es la continuidad de una tradición que se mantiene y se renueva mediante un proceso de reapropiación (del objeto tradición por parte de los sujetos y viceversa) que se desarrolla sobre la base de "evidencias" de tipo retórico (Vattimo, 1987, pp. 122-123).

Se cuestiona las “tradiciones" en las formas de desarrollar el conocimiento científico y se acusa su sustentabilidad y evidencias como retóricas. Se cree que es un grupo el que arbitrariamente en su consenso establece las cosas. No se contempla el valor del profesional especializado y se relativiza su juicio neutral. Pero más aún, se hace una generalización apresurada asumiendo todas estas supuestas indebidas tradiciones o retóricas, relativizando las mismas. Una vez más se cae en falacias argumentales de tipo falsa generalización y falsa causa.

...la creencia en la superioridad de la verdad sobre la noverdad o sobre el error es una creencia que se impuso en situaciones vitales determinadas (...) y que, por otra parte, se funda en la convicción de que el hombre puede conocer las cosas "en sí mismas", lo cual se revela empero imposible, ya que precisamente el análisis químico del proceso del conocimiento revela que el conocimiento no es otra cosa que una serie de metaforizaciones que van de la cosa a la imagen mental, de la imagen que expresa el estado del individuo y de esta palabra impuesta como la palabra "justa" por las convenciones sociales, y luego de nuevo, de esta palabra canonizada a la cosa de la cual percibimos sólo los rasgos fácilmente susceptibles de expresarse en metáforas en el vocabulario que hemos heredado (p. 147). 
Se asume que el conocimiento es solo una convención social, metaforizaciones sin sustentabilidad satisfactoria posible. Se trata de una relativización extrema y una generalización apresurada, pues dicha pretensión de invalidez del conocimiento objetivo es extendida a cualquier convención de personas incluso especialistas; no importa que metodología usen, puedan crear o desarrollar y que rigurosos sean. $Y$ esto incluye a todos los planos del conocimiento y de las ciencias. Falsa generalización, en suma.

Y así también en su obra No ser Dios (Vattimo, 2008) vemos:

Es el fin de la metafísica, el fin del tomismo, pero también el canto del cisne del positivismo; la verdad no puede ser el reflejo objetivo de datos de hecho (...) Si el mundo se reduce al resultado del experimento científico, el mundo verdadero ya no existe. Si el ser verdadero es sólo lo planificable y calculable, todo el resto - sentimientos, miedos, amores ... - es basura, desechos. Termina así la idea de verdad como correspondencia entre afirmación y dato de hecho (p. 57).

Aquí observamos errores categoriales, pretendiendo equiparar conocimiento científico u objetivo con los planos subjetivos de las percepciones desde los sentimientos, miedos y etc. $Y$ no se trata de hacer calificaciones o adjetivaciones sobre ello, son solo diferentes ámbitos o dimensiones de la realidad que deben abordarse adecuadamente en sus respectivos contextos.

Así pues, el concepto es, siempre, éste: lo real se da, pero dentro de ciertos paradigmas. Se puede establecer si una proposición es verdadera o falsa, pero sólo dentro de paradigmas: un momento histórico, una determinada disciplina científica. (...) Yo lo interpretaría así: la realidad son las fórmulas, no los hechos particulares. El hecho particular no prueba nada, como máximo refuta, como diría Karl Popper, que siempre ha seguido pensando que una refutación nos acercaría a la verdad, una verdadera estupidez. Del hecho de que una hipótesis esté equivocada no se extrae nada (Vattimo, 2008, p. 218).

En este caso, Vattimo reconoce la existencia de una realidad pero condicionada por paradigmas, un marco histórico y disciplinar. Sin embargo, considera que estas son solo interpretaciones, relativizaciones en suma.

Y finalmente, en su obra Adiós a la verdad (2010), Vattimo nos sintetiza sus impresiones críticas sobre la verdad y la objetividad, incurriendo una vez más en errores categoriales, algunas falacias no formales, reduccionismos y generalizaciones como podemos ver al respecto en las siguientes citas:

Tal ocaso de la idea de verdad objetiva en la filosofía y en la epistemología aún no parece haber entrado en la mentalidad común, la cual todavía se haya muy ligada, como nos enseña el escándalo sobre los “mentirosos" Bush Y Blair, a la idea de lo verdadero como descripción objetiva de los hechos (pp. 10-11)

La conclusión a la que intento llegar es que el adiós a la verdad es el inicio, y la base misma, de la democracia. Si existiera una verdad "objetiva" de las leyes sociales y económicas (la economía no es una ciencia natural), la democracia sería una elección por completo irracional: sería mejor confiar el Estado a los expertos, a los reyes - filósofos de Platón o a los premios Nobel de todas las disciplinas (p. 18) 
En las citas anteriores observamos el error categorial de pretender equiparar la producción y desarrollo del conocimiento verdadero y objetivo en la ciencia con la cuestión política, sus dinámicas de generación de información y los juicios de valor e intereses que conlleva. Esto se hace al citar como referencias, casos muy particulares de personajes políticos como Bush y Blair (en este caso se trató de la justificación que hizo el gobierno de EEUU y Gran Bretaña para la guerra con Irak). Se trata también de casos circunstanciales que no se pueden generalizar. Por otro lado, la ciencia y el conocimiento objetivo que se obtiene es un instrumento del cual podemos hacer uso, no es algo bueno, malo, justo o injusto en sí. Más bien nos hacemos responsables al hacer uso de dicho conocimiento, no siendo racional pretender eliminar u oscurecer dicho conocimiento por expresar algo que no gusta. Y en el ámbito político, al hacer una elección democrática nos hacemos también responsables por quienes votamos, tanto por el nivel de profesionalismo y objetividad como por sus condicionamientos morales y axiológicos. Ciencia, conocimiento verdadero u objetivo y la esfera de los valores junto con la política; son pues, dimensiones o categorías diferentes.

Tomar en consideración que el problema del consenso sobre las elecciones individuales es sobre todo un problema de interpretación colectiva, de construcción de paradigmas compartidos o de algún modo explícitamente reconocidos, es el desafío de la verdad en el mundo del pluralismo posmoderno (Vattimo, 2010, p. 19)

Puesto que la verdad es siempre un hecho interpretativo, el criterio supremo en el cual es posible inspirarse no es la correspondencia puntual del enunciado respecto de las "cosas", sino el consenso sobre los presupuestos de los que se parte para valorar dicha correspondencia. Nadie dice nunca toda la verdad, sólo la verdad y nada más que la verdad. Cualquier enunciado supone una elección de lo que nos resulta relevante, y esta elección nunca es "desinteresada"; incluso los científicos, que se esfuerzan por dejar de lado en su trabajo las preferencias, las inclinaciones y los intereses particulares, buscan la "objetividad" para llegar a alcanzar resultados que puedan repetirse y así ser utilizados en el futuro. Quizá solo buscan ganar un premio Nobel, y también éste es un interés (Vattimo, 2010, pp. 28 - 29)

Solo podemos reconocer que vemos las cosas con ciertos prejuicios y con ciertos intereses de base, y que si acaso es posible la verdad, ésta es el resultado de un acuerdo que no necesitó de evidencia definitiva alguna, sino de la caridad, la solidaridad y la necesidad humana (¿demasiado humana?) de vivir en paz con los demás. ¿Decir todo esto - amar al prójimo es un deber, la solidaridad es mejor que la lucha - significaría que, como una $\mathrm{P}$ fuera de las comillas, lo creemos porque es un hecho? Tal vez ni siquiera Tarski en persona lo afirmaría (Vattimo, 2010, pp. 53 - 54)

Una vez más, encontramos en estas citas generalizaciones y atingencias que pretenden justificar la invalidez e imposibilidad de un conocimiento verdadero y objetivo. Por un lado, tenemos la pretensión de asumir que solo hay interpretaciones y consensos sin importar el tipo o nivel de sustentabilidad que se tenga, siendo pues un tipo de falacia de generalización apresurada. Y por otro lado, creer que solo se puede partir de prejuicios e intereses, los cuales al final solo se definen en acuerdos o consensos siempre interesados. Se incurre así en falacias de generalización con conclusiones inatingentes, asumiéndose causas que parecen más adjetivaciones, y que no abordan el fondo del desarrollo del conocimiento en las diferentes ciencias. Y ello con la pretensión de deslegitimar todo intento de desarrollo de un conocimiento verdadero y objetivo sustentable rigurosamente. 
Vattimo crítica la pretendida universalidad de la ciencia y sus reglas. Para él se trata más bien de solo retórica que puede ser a lo sumo de alguna forma paradigmática. Y que más bien se utiliza para controlar e imponer desde acuerdos de grupos disciplinares institucionalizados ciertas formas de abordar la realidad con todas sus consecuencias. Así, Vattimo niega en suma la supuesta correspondencia de las ideas con los hechos que postula la ciencia desde sus diferentes perspectivas o aproximaciones, así como la pretendida búsqueda de verdades o hechos objetivos. Una vez más se cae en generalizaciones y errores categoriales al aplanar diferentes tipos de experiencias subjetivas, conocimientos, campos del saber y metodologías de investigación. Todos los aportes que estas disciplinas o metodologías en desarrollo constante puedan dar, junto con el honesto trabajo y capacidades de diferenciación y juicio de sus intelectuales; son minimizadas en sus alcances adjetivándolas como discursos retóricos convertidos en reglas y tradiciones bajo el control de grupos de “ilustrados" siempre interesados y con poder para determinar lo correcto o no, lo válido o descartable. Se trata también de un reduccionismo ideológico y político en la determinación de la validez de las ideas y los hechos el asumido por Vattimo.

\subsection{En Michel Foucault}

Es considerado por algunos como el fundador de la escuela francesa denominada posmodernismo; desarrolla su pensamiento bajo la influencia del giro lingüístico centrando su análisis filosófico en el sujeto de la experiencia ubicado en un mundo exterior (Stokes, 2009).

Miller (2009) refiere lo complejo del estudio de Foucault, pues plantea sus obras en cierta forma autobiográficas. En ese sentido, Foucault entiende el saber y la verdad como el resultado de luchas y confrontaciones dentro de la sociedad, la fuerza de la palabra libre (Castro, 2016). También puede verse en el enfoque foucaultiano, la relación entre la verdad, la subjetividad y el poder (Raffin, 2019). En suma, la imbricación entre lo epistemológico y lo ontológico político (Dalmau, 2020)

Su infructuosa experiencia de vida le permitió analizar la realidad de manera particular. Se interesó por el estudio de temas relacionados con el poder, el control social y las instituciones, el cuerpo, la psique y la sexualidad. Cabe mencionar que Nietzsche fue un referente importante en su visión teórica y analítica (Monge, 2015). Así también con su percepción de ser diferente, con el poder y goce de serlo; $y$, además del psicoanálisis que también influyó en él, especialmente en la vertiente lacaniana; siendo la psicología pues objetivo de su análisis crítico (Pavón Cuellar, 2020). En tal sentido, hay una referencia omnímoda al psicoanálisis en su influencia por los conceptos de la búsqueda del placer y la represión, algo muy común en su época; por la preeminencia de esta corriente, pero que luego se fue devaluando. Sin embargo, aún es muy vigente actualmente, pero dentro de las ciencias sociales en particular.

Otro aspecto que marcó su vida fue el pensamiento marxista, que si bien lo criticó por la interpretación reductiva de la lucha de clases; también lo asume dentro de un sociologismo o determinismo de las condiciones o estructuras sociales e institucionales, así como las dinámicas "históricas" en el devenir de las personas y las sociedades de las cuales forman parte. 
Dentro de las aproximaciones de Foucault también encontramos errores categoriales y falacias argumentales. Así, el saber y/o la verdad para Foucault, se encuentra pues supeditada a condiciones no objetivas. El significante en los discursos es relativizado, ya que se pone en entredicho la condición de los actores y sus intereses institucionales y sociales por las condiciones en las que se encuentran enmarcados. Así, se acusa y generaliza a los sujetos sociales como personajes comprometidos éticamente e interesados inexorablemente por determinadas razones sociales y políticas; tanto como por la determinación de los referentes ideológicos o de "creencias" establecidos y dominantes. Por otra parte, se cae en el error categorial en lo que respecta al método y su rigurosidad o pertinencia en la búsqueda de conocimiento, pues esto es dejado de lado o simplemente subestimado, asumiendo arbitrariamente la cuestión social e institucional y el poder (a nivel externo e interno), expresado en la cuestión del régimen definido en la determinación de los enunciados científicos; es decir, el factor político como imperativo en sus efectos coercitivos o coactivos en la constitución del conocimiento según determinados intereses dentro de las relaciones de dominación (técnicas polimorfas del poder).

Hay pues una generalización en el juzgamiento o relativización de los argumentos que definen las ideas y los hechos, así como errores categoriales y causales al pretender igualar cualquier tipo de discurso o argumentación, sometiéndolas a consideraciones ajenas a la misma producción sustancial del conocimiento objetivo científico.

En este sentido, Foucault pretende hacer patente esto en diferentes temas, como por ejemplo en sus estudios de casos sobre la sexualidad y la enfermedad mental o la locura. Veamos en sus diferentes textos:

En su obra El orden del discurso (Foucault, 2005) podemos leer:

...pues el discurso -el psicoanálisis nos lo ha mostrado- no es simplemente lo que manifiesta (o encubre) el deseo; es también el objeto del deseo; pues -la historia no deja de enseñárnoslo- el discurso no es simplemente aquello que traduce las luchas o los sistemas de dominación, sino aquello por lo que, y por medio de lo cual se lucha, aquel poder del que quiere uno adueñarse (p. 15).

Se asume al psicoanálisis y la historia como fuentes indiscutibles de una verdad "demostrada". Esta es una falacia de tipo petición de principio, pues se asumen ciertas ideas o premisas como si fueran verdades inobjetables, siendo el razonamiento de tipo circular. Además, se pone de relieve al poder o control sobre el discurso más que a los contenidos de sustentabilidad racional misma, siendo este un tipo de falsa causa.

Pues esta voluntad de verdad, como los otros sistemas de exclusión, se apoya en una base institucional: está a la vez reforzada y acompañada por una densa serie de prácticas como la pedagogía, el sistema de libros, la edición, las bibliotecas, las sociedades de sabios de antaño, los laboratorios actuales. Pero es acompañada también, más profundamente sin duda, por la forma que tiene el saber de ponerse en práctica en una sociedad, en la que es valorado, distribuido, repartido y en cierta forma atribuido (Foucault, 2005, p. 22). 
Se postula que estamos inmersos inexorablemente en un contexto que determina la forma en que se generan y expresan las ideas del cual no podemos salir. Sin embargo, esto es muy diferente a pretender asumir que es inútil cualquier intento de búsqueda de objetividad, sin importar que metodologías se utilice, cree o desarrolle. No se puede negar que hay ciertas condiciones sociales, culturales e incluso institucionales que pueden establecer ciertos límites. Sin embargo, esto no debe generalizarse a todas las sociedades o instituciones en cuanto a la libertad, flexibilidad, recursos y capacidades de los mismos sujetos como seres conscientes y en condiciones de hacer observaciones analíticas y estudios objetivos con rigurosidad, independencia y honestidad profesional; incluso cuestionando sus propios marcos idiosincráticos y culturales. Se trata de una falacia argumental de tipo circunstancial (situaciones o características muy particulares) y también de generalización.

\begin{abstract}
Finalmente, creo que esta voluntad de verdad apoyada en una base y una distribución institucional, tiende a ejercer sobre los otros discursos -hablo siempre de nuestra sociedad una especie de presión y de poder de coacción. Pienso en cómo la literatura occidental ha debido buscar apoyo desde hace siglos sobre lo natural, lo verosímil, sobre la sinceridad, y también sobre la ciencia -en resumen, sobre el discurso verdadero-. Pienso igualmente de qué manera las prácticas económicas, codificadas como preceptos o recetas, eventualmente como moral, han pretendido desde el siglo XVI fundarse, racionalizarse y justificarse sobre una teoría de las riquezas y de la producción; pienso además en cómo un conjunto tan prescriptivo como el sistema penal ha buscado sus cimientos o su justificación, primero naturalmente, en una teoría del derecho, después, a partir del siglo XIX, en un saber sociológico, psicológico, médico, psiquiátrico: como si la palabra misma de la ley no pudiese estar autorizada en nuestra sociedad más que por el discurso de la verdad (Foucault, 2005, p. 23).
\end{abstract}

En este caso, los sistemas de ideas y conocimientos sobre un orden establecido son relativizados no contemplando el desarrollo progresivo y su mejoramiento a lo largo de la historia. Se trata de una falacia de tipo circunstancial que solo restringe la observación a momentos de la historia sin contemplar el avance o desarrollo comprobable, en este caso de los diferentes campos del conocimiento y de la sociedad.

Asimismo, en su curso en el Collège de France (1970-1971) desarrolló sus lecciones sobre la voluntad de saber diciendo lo siguiente:

Se trataría de saber si la voluntad de verdad no es tan profundamente histórica como cualquier otro sistema de exclusión; si, en sus raíces, no es tan arbitraria como ellos; si no es modificable como ellos en el transcurso de la historia; si no se apoya como ellos y si, como ellos, no es reactivada sin cesar por toda una red institucional; si no forma un sistema de coacción que se ejerce no sólo sobre otros discursos, sino sobre toda una serie de prácticas. Se trata, en suma, de saber qué luchas reales y qué relaciones de dominación intervienen en la voluntad de verdad (Foucault, 2014, p. 18).

Se contempla la dominación y la coacción como elementos determinantes en la definición de la verdad o de un determinado discurso. Una vez más, ésta es una falacia de tipo Causa falsa y de tipo circunstancial según el caso, pues solo se asume una posibilidad, la lucha por el poder en 
general sobre el control de un discurso. No se cree que sea posible otros factores que puedan contribuir en el desarrollo de procesos rigurosos, objetivamente sustentados, transparentes y neutros.

También en su obra La historia de la sexualidad. La voluntad de saber (2007) Foucault nos dice lo siguiente:

Se nos explica que si a partir de la edad clásica la represión ha sido, por cierto, el modo fundamental de relación entre poder, saber y sexualidad, no es posible liberarse sino a un precio considerable: haría falta nada menos que una trasgresión de las leyes, una anulación de las prohibiciones, una irrupción de la palabra, una restitución del placer a lo real y toda una nueva economía en los mecanismos del poder; pues el menor fragmento de verdad está sujeto a condición política. Efectos tales no pueden pues ser esperados de una simple práctica médica ni de un discurso teórico, aunque fuese riguroso (p. 11).

La política y los mecanismos de poder son considerados por Foucault, como aspectos fundamentales en la configuración del saber y la sexualidad. Ciertamente, estos son temas complejos, pero pertenecen a dimensiones o categorías diferentes. Particularmente, el saber de la ciencia, que también implica sus procesos de desarrollo, maduración y progreso a lo largo de los años, en sus formas y dinámicas de producción de conocimiento. Y, por otro lado, las consideraciones políticas, éticas y morales que se dan en un determinado momento y contexto sociocultural. Es cierto que asumiendo casos extremos, ha habido y habrán situaciones a lo largo de la historia de las sociedades, en donde se generan interferencias y abusos por parte de diferentes gobiernos o instituciones, por su planteo de normas de control, códigos culturales internos o externos incluso, hasta con la persecución de toda idea y persona, incluyendo pensadores, científicos y otros que no se ajusten a lo establecido o a determinados parámetros e intereses. A veces esto puede darse de forma ya normalizada con coerción, coacción, ya sea pacífica o violentamente, como en los regímenes dictatoriales comunistas, en las políticas de determinadas instituciones y otras situaciones organizacionales y culturales. Sin embargo, estos constituyen errores categoriales al pretender asumir de manera inexorable, la dependencia del análisis y desarrollo del conocimiento científico desde factores ajenos al desarrollo mismo de dicho conocimiento en sus procesos metodológicos. Y asimismo, constituyen falacias argumentales de generalización y de tipo circunstancial, el plantear que todo tipo de conocimiento objetivo y científico, solo sea derivación de estos factores externos o extracientíficos como son los criterios ideológicos, políticos, valorativos, intereses económicos y etc.

Y en su obra Estrategias de poder (Foucault, 1999):

Existe un combate «por la verdad», o al menos «en torno a la verdad» -una vez más entiéndase bien que por verdad no quiero decir "el conjunto de cosas verdaderas que hay que descubrir o hacer aceptar", sino "el conjunto de reglas según las cuales se discrimina lo verdadero de lo falso y se ligan a los verdaderos efectos políticos de poder", entiéndase asimismo que no se trata de un combate «en favor» de la verdad, sino en torno al estatuto de verdad y al papel económico-político que ésta juega. Hay que pensar los problemas políticos de los intelectuales no en términos de «ciencia/ideología» sino en términos de 
«verdad/poder». Y a partir de aquí la cuestión de la profesionalización del intelectual, de la división entre trabajo manual/trabajo intelectual, se puede contemplar de nuevo (p. 54). La «verdad» está ligada circularmente a los sistemas de poder que la producen y la mantienen, y a los efectos de poder que induce y que la acompañan, al «régimen» de verdad. (...) No se trata de liberar la verdad de todo sistema de poder - ya que esto sería una quimera, pues la verdad es, por sí misma, poder -, sino más bien de separar el poder de la verdad de las formas hegemónicas (sociales, económicas, culturales) en el interior de las cuales funciona, por el momento. La cuestión política, en suma, no es el error, la ilusión, la conciencia alienada o la ideología; es la verdad misma (p. 55).

Vemos que Foucault sí reconoce la importancia de procurar evitar la influencia perniciosa de intereses económicos, políticos y de otro tipo del desarrollo de la "verdad"; pero también plantea un reduccionismo sociológico y político como elementos que constituyen o enmarcan la realidad de lo aceptable o verdadero. De esta forma, se hace una indebida generalización al negar toda posibilidad de que pueda darse un tipo de conocimiento objetivo sin condicionamientos sociales y políticos que lo distorsionen en su misma sustancia; en su imagen de la realidad expresada en las ideas a partir de los hechos. Los diferentes planos categoriales del conocimiento de la realidad y sus disciplinas de investigación, junto con sus metodologías; son aplanados por igual en su efectividad para abordar la realidad objetiva, esta simplemente se niega arbitrariamente planteando casos particulares o circunstanciales, de petición de principio y monocausales como hechos universales bajo una retórica persuasiva y emotiva.

Ciertamente, Foucault afirma que la posesión de cualquier verdad, concepto que más bien considera como ideología, conciencia alienada o ilusión de su contexto histórico temporal; puede ser determinante para establecer pautas de control de una sociedad, siendo esta su preocupación. Pues esto puede ser un riesgo para algunos o muchos dentro de sus disposiciones de libertad. Sin embargo, al margen de las consideraciones relativistas de Foucault, este es un desafío que toda sociedad debe asumir en su pretensión de equilibrar la libertad y el derecho junto con el desarrollo de conocimiento científico y procurando que este sea objetivo respetando los respectivos límites categoriales de la realidad respecto a otros campos o materias del saber y de las artes.

\section{Conclusiones}

Ha sido posible identificar la existencia de diferentes errores categoriales, así como algunas falacias argumentales, dentro del desarrollo discursivo de los autores; en lo que respecta a su fundamentación y cuestionamiento sobre el desarrollo del conocimiento científico, la verdad y la objetividad. Estos son en suma relativizados, al asumir niveles o categorías distintas de temas o conceptos como la política, las artes y las ciencias de igual forma. Se hacen generalizaciones o reduccionismos en cuanto a relaciones, causas o consecuencias. Al respecto, es necesario estar familiarizado con la identificación de estos elementos discursivos dentro de los tipos de argumentación, situación que no es compartida en su conocimiento y ejercicio crítico por buena parte de la comunidad, ya sea académica o no; y que puede afectar el desarrollo dentro de las ciencias naturales, sociales y humanísticas, así como su adecuada expresión sustentable. 
Asimismo, si bien es posible identificar dichos elementos, muchas veces esto no es tan claro dentro de los discursos de las ciencias sociales y humanísticas; lo cual hace necesario desarrollar una cierta práctica y agudeza, además de procurar hacer a un lado ciertos condicionamientos del ejercicio mismo del lenguaje cotidiano ya sea a nivel oral o escrito, tanto como posibles prejuicios ideológicos de tipo político y cultural que son justo parte del mismo debate epistemológico.

Y ciertamente, cabe mencionar que en las ciencias sociales principalmente, hay un particular compromiso muy marcado con la realidad social y política en la búsqueda de respuestas y cambios. Esto es dentro de lo que Max Weber (1919) ya ha planteado hace un poco más de cien años, respecto a la ética del político y el científico en su obra La ciencia como profesión, la política como profesión. Hacer esta diferenciación dentro de la conciencia de cada profesional de las ciencias sociales y humanísticas, no es en muchos casos tarea fácil y hasta puede ser un desafío. Sin embargo, es una tarea que debemos asumir para no caer en los reduccionismos disciplinares, afanes ideológicos militantes o en el subjetivismo.

El pensador posmoderno se identifica por su rechazo a cualquier forma posible de configuración de leyes universales o de verdades fundamentales, asume un criticismo ante la realidad actual y da legitimidad a diferentes tipos de discurso incluyendo a las artes y la literatura como fuentes válidas de conocimiento equiparable a lo científico. Se centra en la vida subjetiva del sujeto, validando la experiencia misma y particular, incluyendo las emociones y sentimientos, como fuente valiosa y válida de conocimiento. Así también, en los diferentes discursos posmodernos, se considera a la verdad y la objetividad solo como interpretaciones siempre sujetas a consensos y marcos socioculturales, los cuales se condicionan por determinados intereses.

Sin embargo, la visión crítica posmoderna se caracteriza por hacer generalizaciones o reduccionismos indebidos de los hechos desde casos o situaciones particulares, validando interpretaciones desde lo subjetivo y emitiendo juicios de valor que ponen de relieve la experiencia o vivencia personal. Es decir, se apela al subjetivismo y además, se asumen errores categoriales que se expresan en las consideraciones políticas o sociales dentro de una retórica persuasiva argumental.

De tal modo que, el error categorial, ya muy característico en las ciencias sociales de orientación posmoderna, se encuentra en muchos casos teñido de subjetividad y relativismo. Es decir, las formas de desarrollar u obtener el conocimiento son reducidas a consideraciones e intereses de tipo político, valorativo, económico, emotivo y vivencial. Todo ello se confunde en un mismo plano, haciendo, curiosa y contradictoriamente, reduccionismos deterministas. $Y$ en el mejor de los casos, se acepta reconocer o negar consideraciones verdaderas o falsas respectivamente solo dentro de los marcos reductivos paradigmáticos y con su relativización, siendo todo esto cambiante o sujeto a circunstancias ajenas a la propia naturaleza intrínseca del desarrollo del conocimiento.

Así encontramos en diferentes argumentos, la utilización de falacias argumentales no formales como de tipo ad veracundiam o falacia de autoridad, la generalización apresurada, la falacia de correlación y causalidad impropias en determinado argumento, y las falacias de generalización con conclusiones que son inatingentes o de situaciones circunstanciales que no tienen que ver 
con el trasfondo del tema. En suma, estos tipos de argumentos falaces son utilizados de manera consciente o inconsciente para defender o justificar una creencia o postura ideológica; así como para la generación de una opinión favorable prescindiendo de las necesarias y justas validaciones lógicas racionales.

Es importante considerar que la sociedad del siglo XXI se caracteriza por su alta complejidad y atomización, lo cual implica asumir una visión multi o interdisciplinaria para superar los sesgos disciplinares, metodológicos y valorativos. Se debe procurar un equilibrio en el razonamiento que integre lo subjetivo y lo objetivo sin caer en reduccionismos o generalizaciones indebidas. Para ello el uso adecuado de metodologías cualitativas, cuantitativas y mixtas se hace imperativo, así como su constante y progresivo mejoramiento o perfeccionamiento; pero abordando la realidad en su representación de manera no arbitraria y menos subjetiva, teniendo cuidado en respetar las diferentes dimensiones categoriales de la realidad.

Además, es necesario mantener una postura deontológica y crítica ante intereses ya sean políticos, económicos, sociales, culturales y otros que puedan distorsionar los procesos del desarrollo del conocimiento y particularmente el de tipo categorial científico.

Y finalmente, dentro de las dificultades para el desarrollo del artículo y en general para mejorar nuestras aproximaciones a la realidad de manera objetiva, está la necesidad de desarrollar una cierta práctica y agudeza para identificar los diferentes tipos de argumentos y las posibles sutilezas que evoquen falacias o errores categoriales; además de procurar hacer a un lado ciertos condicionamientos del ejercicio mismo del lenguaje cotidiano ya sea a nivel oral o escrito, tanto como posibles prejuicios ideológicos de tipo político y cultural que son justo parte del mismo debate epistemológico.

\section{Referencias}

Castro, E. (2016). La verdad del poder y el poder de la verdad en los cursos de Michel Foucault. Tópicos, Revista de Filosofía de Santa Fe, (31), 42-66. https://doi.org/10.14409/topicos.voi31.7959

Casullo, N. (2004). El debate modernidad - posmodernidad: Edición ampliada y actualizada. Retórica ediciones

Dalmau, I. G. (2020). Revisitando la crítica de las ciencias humanas elaborada por Michel Foucault en sus cursos sobre biopolítica y gubernamentalidad. Praxis Filosófica, (51), 97-114. https://doi.org/10.25100/ pfilosofica.voi51.9950.

Foucault, M. (1977). La historia de la sexualidad. La voluntad de saber. Siglo XXI.

Foucault, M. (1986). Estrategias de poder. Paidós.

Foucault, M. (1996). El orden del discurso. Siglo XXI.

Foucault, M. (2014). Lecciones sobre la voluntad de saber: curso en el Collège de France (1970-1971). Fondo de Cultura Económica.

Gavela González, R. (2011). La nueva ciencia. Hallazgos, 8(16), 29-41. https://doi.org/10.15332/s17943841.2011.0016.02

Guerra, G. Y. M. (2011). Narrativa y ciencia. La importancia de las palabras en la investigación. Hallazgos, 9(17), 121-141. https://doi.org/10.15332/s1794-3841.2012.0017.04

Miller, J. (2011). La pasión de Michel Foucault. Tajamar editores.

Monge, J. (2015). Vida, verdad y error en el último Foucault. Mutatis Mutandis: Revista internacional de filosofía. 4, 135-149. https://revistamutatismutandis.com/index.php/mutatismutandis/article/view/115 
Pavón-Cuellar, D. (2020). Michel Foucault, su inconfesado marxismo y su crítica de la psicología. Athenea Digital, 20(1), e-2229 https://raco.cat/index.php/Athenea/article/view/372120

Paz y Miño Conde, M. A. (2019). La enseñanza de la filosofía de la ciencia en el Perú en la actualidad. $P U R I Q, 1$ (01), 19-32. https://doi.org/10.37073/puriq.1.01.7

Raffin, M. (2019). Verdad y subjetividad en Michel Foucault (1970-1980). Editorial Teseo.

Ryle, G. (1949). The Concept of Mind. Bames \& Noble, Inc.

Stokes, P. (2009). Cien pensadores esenciales. Panamericana editorial.

Vattimo, G. (1987). El fin de la modernidad. Editorial Gedisa.

Vattimo, G. (2008). No ser Dios. Paidós.

Vattimo, G. (2010). Adiós a la verdad. Editorial Gedisa.

Weber, M. (2007). La ciencia como profesión. La política como profesión. Editorial Espasa Calpe.

\section{AUTOR}

Héctor Cáceres Bejarano. Maestrando en las especialidades de Epistemología de las ciencias y en Arqueología andina, Universidad Nacional Mayor de San Marcos. Bachiller en psicología con orientación social comunitaria y organizacional. 